\title{
DO DANO MORAL AO EXTRAPATRIMONIAL: A NECESSIDADE DE IDENTIFICAÇÃO DOS DIREITOS E INTERESSES LESADOS
}

\author{
Ana Cláudia Corrêa Zuin Mattos do Amaral ${ }^{1}$ \\ Maiara Santana Zerbini ${ }^{2}$
}

\section{Resumo}

Analisa o dano moral como uma subespécie de dano extrapatrimonial, com o intuito de apontar o bem ou interesse juridicamente relevante a ser tutelado. Para tanto, demonstra a insuficiência do comum apelo ao aspecto sentimental, intelectual, valorativo individual e social da personalidade que permeia a definição clássica de dano moral, e constrói uma conceituação dessa espécie de dano extrapatrimonial como a ofensa à esfera ética do indivíduo posta em uma determinada sociedade. Ao final, examina como a distinção estabelecida entre extrapatrimonial e dano moral reflete na finalidade ressarcitória da responsabilidade civil enquanto dever ético-jurídico.

Palavras-chave: Dano moral. Dano extrapatrimonial. Responsabilidade Civil. Função ressarcitória. Dever jurídico.

\section{FROM MORAL DAMAGE TO EXTRAPATRIMONIAL: THE NEED FOR IDENTIFICATION OF LESTE RIGHTS AND INTERESTS}

\begin{abstract}
Analyzes moral damages as a subtype of non-material damages, in order to indicate the legally relevant asset or interest to be protected. It thus demonstrates the insufficiency the common appeal to feelings, intellect, individual and social value of the personality that permeates the classic definition of moral damages, and constructs a conceptualization of this kind of non-material damage as the offence to the ethical sphere the individual in the context a given society. Finally, it examines how the distinction made between non-material damanges and moral damages is reflected in the compensatory purpose of civil responsibility as an ethical-legal duty.
\end{abstract}

Keywords: Moral damage. Extra-financial damages. Civil responsability. Restatement function. Legal duty.

\section{Introdução}

\footnotetext{
${ }^{1}$ Doutora em Direito das Relações Sociais, Área de Concentração em Direito Civil Comparado pela PUC-SP

${ }^{2}$ Mestranda em Direito Negocial pela Universidade Estadual de Londrina/PR - UEL, bolsista CAPES. PósGraduada em Direito e Processo Civil pela Universidade Estadual de Londrina/PR - UEL.
} 
Os regramentos jurídicos, antes essencialmente patrimonialistas, ganharam nova conotação ao longo do tempo. Com os acontecimentos históricos e o próprio desenvolvimento das civilizações, observou-se a necessidade de adotar parâmetros para resguardar a própria existencialidade humana.

O reconhecimento dos direitos e garantias fundamentais, bem como a consagração da dignidade humana como princípio constitucional refletiram em todas as esferas jurídicas, ampliando os direitos e interesses juridicamente relevantes considerados no campo da existencialidade, como por exemplo, os direitos coletivos, sociais e difusos.

Ponderando um dano ocorrido no mundo fático frente à extensão das possibilidades ressarcitórias, a divisão da classificação entre dano patrimonial e dano moral se revelou insuficiente e restritiva ao alcance da tutela jurisdicional. Por essa razão é que se justifica o presente, pois a abordagem conceitual do dano moral, assim como o debate sobre a distinção entre este e o dano extrapatrimonial prevê o exercício justo e efetivo do instituto da responsabilidade civil no que tange a reparação e a compensação da lesão suportada pela vítima.

Para que se alcance tal objetivo, será preciso compreender que a extensão dos danos existentes na esfera extrapatrimonial, vai além da lesão em que decorre o dano moral, sobrepujando-o, ou seja, os danos extrapatrimoniais podem decorrer de outros deveres jurídicos, que não aqueles que incitam o dano moral. Dessa forma, a aplicação da terminologia "dano extrapatrimonial" como gênero e não congênere aos danos morais, afastando incoerências e efetivando a real função do instituto da Responsabilidade Civil, revelar-se-á mais adequada.

Com o enquadramento e diferenciação dos direitos inerentes à pessoa concretamente considerada, será possível, de maneira mais eficaz e justa, delimitar o dever jurídico perseguindo e mais precisamente qual bem ou interesse jurídico foi lesionado. Assim, a função ressarcitória desempenhada pelo instituto da responsabilidade civil cumprirá o seu dever ético-jurídico, reequilibrando a relação desenvolvida pelos indivíduos inseridos em uma determinada sociedade.

A fim de desvendar a problematização eleita, segundo as bases lógicas de investigação científica, o estudo aqui empreendido se fundamenta no método dedutivo, propondo a analise nos dados bibliográficos e documentais, com o intuito de compreender o dano extrapatrimonial como gênero do dano moral. Após a busca destas noções por meio das 
bases lógicas de investigação, efetuar-se-á um estudo no tocante à função ressarcitória da responsabilidade civil, demonstrando a necessidade de se identificar o bem ou interesse juridicamente relevante.

\section{COMPREENDENDO DANO MORAL}

O dano vem sendo apresentado desde os primórdios da composição humana, ainda que bem precariamente. A ideia de reparar o "mal" que se causou a outrem pode ser identificada nas previsões do Código de Hamurabi, na Lei das XII Tábuas e na própria Bíblia (VIEIRA, 2011, p. 10). Isso porque a lesão que se afere ao outro, de alguma forma, estabelece o direito à vítima de contrabalancear essa desarmonia relacional, inclusive, a origem do dano advém do próprio fator de relacionamento humano.

No Brasil, a composição do dano sempre fora expressivamente patrimonial, embora haja relatos de previsão moral, por exemplo, a condenação do homem que dormisse com uma mulher virgem e com ela não se casasse, ficando obrigado a solver determinado valor a título de indenização, referente ao dote que ela receberia em razão do casamento, cujo valor era arbitrado pelo julgador, considerando as posses do homem ou de seu pai (FREITAS, 2009, p. 33).

Não obstante, o Código Civil de 1916, também conhecido como o Código de Beviláqua, enfatizava ainda mais a preponderância da expressão humana por meio de seus bens materiais, retratando um código essencialmente patrimonialista. Em uma interpretação restritiva, é possível identificar o interesse moral do requerente, quando da propositura da ação fundamentada no artigo 76 e seu parágrafo único ${ }^{3}$, entretanto, grande não eram as considerações.

O movimento externo que já vinha se desenvolvendo, advindo dos acontecimentos históricos pós $2^{\circ}$ Guerra Mundial, em que as atrocidades e o número de atentados contra a própria raça humana se mostraram assombrosos, afirmavam a necessidade de se reconhecer direitos e garantias fundamentais, possibilitando a existência digna do próprio homem (AMARAL, 2014, p. 77).

\footnotetext{
${ }^{3}$ Código Civil dos Estados Unidos do Brasil - Lei $\mathrm{n}^{\circ}$. 3.071, de $1^{\circ}$ de Janeiro de 1916. Artigo 76. "Para propor, ou contestar uma ação, é necessário ter legítimo interesse econômico, ou moral. Paragrafo único. O interesse moral só autoriza a ação quando toque diretamente ao autor, ou à sua família". Disponível em: <http://www.planalto.gov.br/ccivil_03/leis/L3071.htm〉. Acesso em: 05 fev. 2017.
} 
A compreensão inserida na finalidade de uma existência digna remete à visão de que todas as pessoas possuem, essencialmente, a dignidade, por essa razão, todas devem ser tratadas com mesmo respeito e valimento (SARMENTO, 2016, p. 28). Com efeito, a carga valorativa desse princípio foi estendida ao ponto de ser caracterizado como vetor supremo da análise de toda e qualquer problemática jurídica, existindo a necessidade de um exame interligado ao seu papel normativo, decorrendo, assim, a ampliação da tutela do homem (BONAVIDES, 2001, p. 233).

Todo esse caminhar histórico e jurídico influenciou na composição das normas desencadeando reflexos significativos, os quais afastaram a antiga composição unicamente patrimonialista do Código Civil Brasileiro de 1916, dando lugar à perseguição de finalidades como a existência digna e o bem-estar social.

A elaboração da Constituição Federal brasileira de 1988 configura-se como um verdadeiro divisor de águas, uma vez que modificou todo o paradigma jurídico, afastando o homem como sujeito abstrato, dando lugar à pessoa concretamente considerada (FACHIN; PIANOVSKI, 2008, p. 104).

Em seu manto, a Constituição Federal incluiu a previsão expressa da reparação por danos morais, assegurando em seu artigo $5^{\circ}$, inciso $\mathrm{V}$, o direito à indenização pelos danos materiais, morais ou à imagem e, na sequência do mesmo artigo, no inciso $\mathrm{X}$, dispõe sobre a inviolabilidade da intimidade, da vida privada, da honra e imagem das pessoas, novamente reafirmando a possibilidade de indenização pelo dano material ou moral.

A essa altura não se questionava mais a impossibilidade de se resguardar o ser humano em sua existencialidade, tampouco que a lesão não perpassaria além do âmbito patrimonial, ou seja, a concretização da pessoa não se dava, apenas, sobre o desígnio de seus bens materiais, mas na expressão de sua própria essência.

Todavia, na prática, a "onda" que atingiu o judiciário, bem como as discussões doutrinárias, apresentaram diversas problemáticas em razão do dano moral, em relação à fixação do quantum indenizatório, os critérios adotados para sua estipulação (extensão do conceito) e a infinita gama de possibilidades (MORAES, 2003, p. 25-26). Para o presente estudo, a busca por um conceito, bem como a designação do dano moral como subespécie da esfera extrapatrimonial são indispensáveis para se concretizar uma resposta satisfatória à especificação do bem ou interesse jurídico a ser tutelado. 
Em uma análise geral, o dano, independente de seu enquadramento, advém da composição estrutural do instituto da Responsabilidade Civil, ou comumente conhecido, pressupostos do dever de indenizar. Ainda que não exista uma unanimidade doutrinária sobre quais elementos estruturam a responsabilidade civil, o dano sempre é indicado (TARTUCE, 2016, p. 359-360).

Assim, muitas são as teses que objetivam conceituar o dano como pressuposto indispensável da responsabilidade civil. Fortalecendo a ideia de que, ao falar de direito de responsabilidade civil, a não identificação do dano não possibilita a concretização do dever de indenizar (VON BAR, apud MORAES, 2003, p. 144). Essa concepção é bem lógica, pois decorrido o dano, há o dever de indenizar.

A estrutura como apresentada mostra-se de fácil percepção no momento da análise dos danos patrimoniais, uma vez que esse se traduz no conjunto de relações jurídicas estimáveis em pecúnia (CAVALIERI F., 2005, p. 96). Em uma equação simples, dano patrimonial é a diferença entre o que se tem e o que se teria, não fosse o evento danoso. $\mathrm{O}$ próprio significado da palavra "indenizar" provém do latim, “in dene”, que significa devolver o patrimônio ao estado anterior, isto é, eliminar o prejuízo e suas consequências (MORAES, 2003, p. 143-145). Porém, delimitar o dano quando diligenciado no aspecto existencial não se trata de um fazer singelo.

$\mathrm{Na}$ conceituação tradicional, dano é a diminuição do patrimônio, tanto material, quanto moral. Etimologicamente, dano vem de demere, que significa retirar, depreciar, reduzir, isto é, modificar o estado de bem-estar da pessoa, seguido da diminuição ou perda de qualquer dos seus bens (patrimoniais ou extrapatrimoniais). Assim, há uma tendência doutrinária em indicar o dano moral como oposição ao dano material, sendo este o que atinge bens mensuráveis em pecúnia e aquele, antagônico, o prejuízo a bens ou valores que não têm conteúdo econômico (LOPEZ, 2004, p. 22-24).

Entretanto, tal colocação se mostra insuficiente, uma vez que o dano moral associado a qualquer prejuízo não aferível economicamente apresenta uma conotação tão extensa que afasta o seu sentido jurídico (SCHREIBER, 2013, p. 107). Até porque, considerando os efeitos do dano moral, tanto é possível ocorrer dano patrimonial em consequência de ofensa ao bem não patrimonial, como dano moral por efeito da lesão a bem material (DIAS, 1994, 740-741). 
Na tentativa de delimitar o conceito de dano moral, entende-se que este advém da esfera da subjetividade ou do plano valorativo da pessoa inserida no meio social, objetivando os aspectos mais íntimos da personalidade humana, assim como a própria pessoa no meio em que vive e atua (THEODORO JUNIOR, 2010, p. 02).

Seguindo esse raciocínio, é possível considerar, então, que dano moral pode ser compreendido como aquele que atinge a órbita dos direitos personalíssimos, voltando-se para todo e qualquer atributo que individualiza cada ser humano em sua liberdade, honra, atividade profissional, reputação, manifestações culturais e intelectuais etc. (MORAES, 2003, p. 157).

Para Aparecida Amarante (2005, p. 110-242), “o sujeito de direitos e deveres é resultante de várias faculdades, exercidas sob o manto dos direitos subjetivos", cujo objeto são as projeções físicas e morais da pessoa. Nessa acepção, pode-se compreender por dano moral a lesão que interpela o campo personalíssimo do titular, ou seja, campo sentimental, intelectual e valorativo individual ou social da personalidade

Indo além, o dano moral não necessariamente deve ser reconhecido por direitos que se revelam como direitos subjetivos, ou seja, para efetivar a defesa e a promoção integral da personalidade humana, à pessoa não é imprescindível a titularidade de um direito, mas o inverso. A existência de uma lesão a um dever jurídico que se concretize em direito ou interesse juridicamente relevante já se traduz na essencialidade do reconhecimento do dano moral. Maria Celina Bodin de Moraes (2003, p. 179) afirma que: "a proteção surge primeiro e decorre dela; em seguida, configura-se o direito subjetivo ou direito protestativo, ou faculdade, o que quer que seja mais adequado como estrutura para aquela determinada situação jurídica" .

Dessa forma, também não se pode afirmar que a lesão que ocasiona o dano moral se traduza única e exclusivamente aos direitos da personalidade, tampouco a dor e sofrimento, dado seu caráter excessivamente subjetivo e consequencial. Assim, a definição de dano moral como lesão a um interesse tutelado, mostra-se como a melhor colocação, uma vez que promove a averiguação do objeto da lesão, identificando o interesse da vítima realmente

\footnotetext{
${ }^{4}$ As situações jurídicas devem ser visualizadas por diversos aspectos concorrentes entre eles. Sua concepção ocorre de um fato, humano ou natural, juridicamente relevante, que constitui um núcleo vital e característico, ora patrimonial, ora pessoal e existencial, ora ambos. No seu exercício é possível encontrar uma manifestação de vontade de algum sujeito, não necessariamente do titular do interesse, vez que o sujeito não é parte fundamental da situação jurídica subjetiva, pois esta constitui centros de interesses, que se traduzem na composição de direitos, obrigações, poder jurídico, interesse legítimo, ônus, etc. (PERLINGIERI, 2002, p. 106-108).
} 
violado pelo agente, conferindo-lhe apreço ou não da tutela, possibilitando a apuração dos danos ressarcíveis (SCHREIBER, 2013, p. 109).

Definido o conceito de dano moral como lesão a um direito ou interesse juridicamente tutelado e identificando que sua concretização não se dá exclusivamente em razão da lesão aos direitos da personalidade, mas por meio da ofensa à cláusula geral da dignidade humana (traduzida em seus substratos materiais de igualdade, integridade psicofísica, a liberdade e a solidariedade (MORAES, p. 189)), conclui-se que o dano moral decorre da lesão à esfera ética ${ }^{5}$ de cada indivíduo (MIRANDA, 1959, p. 30), em que sua aferição se dará pela discricionariedade judicial, pois necessária a análise do caso concreto (SCHREIBER, 2013, p. 109).

Levando-se em consideração esses aspectos, torna-se evidente que a conceituação do dano moral interliga-se ao plano valorativo e subjetivo da pessoa inserida em sociedade, objetivando os preceitos éticos do meio em que vive e atua, os quais encontrando substrato na dignidade humana concretizam-se como direitos e interesses juridicamente relevantes merecedores de tutela.

\section{O DANO EXTRAPATRIMONIAL: GÊNERO E NÃO ESPÉCIE}

O dano moral vem sendo apontado ao longo do tempo e timidamente foi ganhando espaço na medida em que a movimentação em favor das tutelas aos Direitos Humanos também se desenvolveram. A elevação da dignidade da pessoa humana como fundamento da República (Art. $1^{\circ}$, inc. III, da CF), bem como toda a conotação internacional designada a esse princípio asseguraram à sua finalidade o substrato de vetor geral para as demais esferas jurídicas, alargando as possibilidades de dano.

Isso significa dizer que, no ordenamento jurídico brasileiro, o princípio da dignidade humana possibilita a existência de um diálogo entre todas as esferas jurídicas, inclusive destas com a constituição. No direito civil, essa mudança de paradigma possibilitou consideráveis reflexos, estabelecendo uma dicotomia essencial entre as relações jurídicas existenciais e as relações jurídicas patrimoniais. Dessa forma, no que tange ao dano, no momento da

\footnotetext{
${ }^{5}$ Ao estabelecer uma ligação entre dano moral e a esfera ética da pessoa, relaciona-se a ofensa aos valores decorrentes do comportamento moral dos indivíduos inseridos em uma determinada sociedade (Vázquez, 2006, p.23).
} 
prevenção da lesão, observou-se também uma transformação extensa na dogmática da responsabilidade civil (TEPEDINO, 2004, p. 170).

A extensão dessas relações existenciais, abarcadas pelo instituto da responsabilidade civil, encontra-se justificada em todo o contexto histórico, inclusive na atualidade, na medida em que os direitos da pessoa se encontram assustadoramente ameaçados, não apenas pelos avanços tecnológicos, mas pela falta de solidariedade e respeito dentro de uma sociedade contemporânea cingida por todos os tipos de violência (LOPES, 2000, p. 18).

É assertiva a afirmação de que a dignidade da pessoa humana está intimamente ligada ao dano, vez que irradia a todos os setores do sistema normativo. É na extensão da dignidade humana que a ordem encontra seu próprio sentido, estabelecendo a origem e os limites da interpretação e aplicação normativa, consagra-se, assim, como lídimo superprincípio a orientar todas as esferas do Direito (PIOVESAN, 2000, p. 90).

Com efeito, amplia-se a extensão dos direitos e interesses juridicamente relevantes a serem considerados no campo da existencialidade, como por exemplo, os direitos da personalidade, coletivos, sociais e difusos ${ }^{6}$, não sendo adequada às finalidades a que se presta o Direito, a indicação única e exclusivamente ao dano moral, tampouco a equiparação dos danos morais aos extrapatrimoniais.

Na doutrina clássica, não é difícil encontrar a conceituação de danos patrimoniais e extrapatrimoniais caracterizados, respectivamente, como dano material e dano moral (SEVERO, 1996, p. 35). Essa distinção entre danos extrapatrimoniais e patrimoniais não se revela como simples fator nominal; antes, porém, acarreta consideráveis consequências em face daquele que recorre ao judiciário para ter seu direito satisfeito. Isso porque o litígio que visa ao ressarcimento dos danos morais como dano extrapatrimonial afasta a possibilidade de indicação das demais espécies, as quais se sujeitam a bens e a interesses distintos daqueles perseguidos pelo dano moral.

A dificuldade encontrada na identificação da lesão quando estabelecida em uma dimensão subjetiva, a qual não parece ser possível delimitar, não significa dizer que não se possa ou deva buscar uma definição, que, não obstante, alcançará pleno sentido e operabilidade em face do caso concreto (SARLET, 2008, p. 60).

\footnotetext{
${ }^{6}$ Flávio Tartuce exemplifica os novos danos em danos estéticos, danos por perda de uma chance, danos morais coletivos, danos sociais e difusos. Argumenta que estes são decorrentes da própria evolução humana, pois na medida em que se reconhecem direitos, a criação de novas tecnologias e que o homem amplia os seus meios de conquistas, consequentemente, surgem novos prejuízos e novas vítimas (TARTUCE, 2016, p. 440).
} 
Nas palavras de Sérgio Severo (1996, p.36), citando Jorge Mosset Iturraspe (1991, p.1-2), considerando um dano real frente ao alargamento das possibilidades ressarcitórias, as expressões dano patrimonial e dano moral atuam como módicas, limitando o alcance da tutela jurisdicional.

A percepção de se ampliar a designação de dano extrapatrimonial também é justificada na dinamicidade da própria pessoa, pois na medida em que o homem se transforma (evolução histórica, tecnológica, biológica etc.) novos direitos e deveres emergem, por conseguinte, novos danos (COUTO E SILVA, 1991, p. 12).

A Constituição Federal de 1988 assegurou a tutela aos danos extrapatrimoniais, quando incluiu a matéria no texto dos direitos fundamentais da pessoa humana ${ }^{7}$, cujo preâmbulo se destina a assegurar o exercício dos direitos individuais e sociais, instituindo como fundamento da República a dignidade da pessoa humana ${ }^{8}$ (FENSTERSEIFER, 2008, p. 119).

A previsão do artigo $5^{\circ}$, inciso $\mathrm{X}$ da Carta Magna, que versa sobre o direito à vida, à liberdade, à igualdade, à segurança e à propriedade como sendo invioláveis, assegurando a indenização pelos danos materiais e morais decorrentes de uma possível lesão, reafirma a indenização os danos extrapatrimoniais, pois se refere ao bem da vida, o qual está resguardado nos direitos da personalidade. Não obstante, a lesão aos direitos da personalidade não é a única espécie de danos extrapatrimoniais ${ }^{9}$ (SEVERO, 1996, p. 90). Melhor seria a utilização do termo extrapatrimonial, afastando a limitação que o vocábulo "moral" instalada.

Nessa acepção, danos extrapatrimoniais podem ser compreendidos como a lesão de interesses sem expressão econômica, em contraposição ao dano patrimonial (SEVERO, 1996, p. 43). Todavia, há de se considerar que nada impede a ocorrência de reflexos econômicos indiretos ou diretos (AMARANTE, 2005, p.127).

Observa-se que a distinção entre dano patrimonial e dano extrapatrimonial não decorre da natureza do direito, bem ou interesse ofendido, mas do efeito dessa ofensa, ou seja,

\footnotetext{
${ }^{7}$ Artigo $5^{\circ}$. "Todos são iguais perante a lei, sem distinção de qualquer natureza, garantindo-se aos brasileiros e aos estrangeiros residentes no País a inviolabilidade do direito à vida, à liberdade, à igualdade, à segurança e à propriedade [...]” - Constituição da República Federativa do Brasil de 1988.

Artigo $1^{\circ}$. A República Federativa do Brasil, formada pela união indissolúvel dos Estados e Municípios e do Distrito Federal, constitui-se em Estado Democrático de Direito e tem como fundamentos: [...] III - a dignidade da pessoa humana; [...] - Constituição da República Federativa do Brasil de 1988.

9 “[...] Não restam dúvidas quanto à reparabilidade dos danos extrapatrimoniais decorrentes de lesão aos direitos da personalidade. Porém, a lesão aos direitos da personalidade é apenas uma das fontes de danos extrapatrimoniais" (SEVERO, 1996, p. 90).
} 
de sua significância sobre o indivíduo lesado (DIAS, 740-741). A distinção das subdivisões do dano extrapatrimonial também ocorre da mesma maneira.

Portanto, é perceptível uma inclinação de cada vez mais distinguirem-se os danos na esfera extrapatrimonial, quantificando de maneira independente, tornando-o consistente de forma a afastar a sua efemeridade e seu subjetivismo, reduzindo-o às capacidades e às potencialidades da qualidade de vida da pessoa (FACCHINI NETO, 2010, p. 55).

Com a especificação dos danos extrapatrimoniais, diferenciando e idealizando o bem jurídico ou interesse, torna-se mais coerente a análise do caso concreto, tendo em vista que, dessa forma, decorrida a lesão, é possível identificar a qual ou quais danos ela atingiu. Ademais, essa concepção facilitaria também a apuração da extensão consequencial da lesão, tornando a tutela jurídica mais justa e eficaz.

\section{A DISTINÇÃo É NECESSÁRIA: COMPREENDENDO A FUNÇÃO EFETIVA E JUSTA DA RESPONSABILIDADE CIVIL}

A discussão manifestada na presente seção faz-se pertinente, haja vista que, ao evidenciar a necessidade de distinção entre dano extrapatrimonial e dano moral, consecutivamente gênero e espécie, objetiva-se uma resposta clara e precisa sobre a disposição dos novos danos e o dever jurídico por ele perseguido. Dessa forma, a função ressarcitória do instituto da responsabilidade civil alcançaria, de maneira satisfatória, a finalidade a que se presta.

O instituto da responsabilidade civil pode ser compreendido como a realização jurídica sob a ótica do personalismo ético, em consonância a isso, ser responsável é atribuir-se as implicações do próprio agir em equilíbrio à faculdade concretizada pela autonomia privada ${ }^{10}$. Em outras palavras, é a situação jurídica em que algum indivíduo se encontra sob a obrigação de indenizar outrem por fato decorrente da própria obrigação (AMARAL, 2014, p. $602)$.

\footnotetext{
${ }^{10}$ A esfera de liberdade que o sujeito dispõe no âmbito do direito privado denomina-se como autonomia, direito de reger-se sobre suas próprias regras. A autonomia privada, por sua vez, constitui o espaço concedido pela legislação aos particulares para que exerçam sua liberdade, permitindo a autorregularão de sues interesses, caracterizando-se na fonte de onde emanam determinados direitos e deveres (AMARAL, 2014, p. 409).
} 
A responsabilidade civil exprime sua importância por ser o instituto que, deliberando sobre as relações sociais que inferem no mundo do Direito, tutela a atividade humana ao mesmo tempo em que reprime aqueles que se posicionam em desacordo com a norma. Ela se respalda sobre o dever jurídico, compreendido como o agir externo de um indivíduo determinado pelo Direito posto (CARVALIERI FILHO, 2005, p. 23).

Para Carlos Alberto Bittar, responsabilidade civil ou obrigação de indenizar é o instituto jurídico que constrange o agente a assumir as consequências sobrevindas da conduta transgressora, reparando ou compensando os prejuízos de ordem patrimonial ou extrapatrimonial (1994, p. 561).

Dessa forma, a responsabilidade civil presume uma relação jurídica entre a pessoa que suportou o prejuízo e a que tem obrigação de repará-lo. O deslocamento do ônus do dano pelo lesado a outro indivíduo, que por previsão legal deverá suportá-lo, reestabelece a harmonia moral, social e jurídica, assegurando sua dignidade (DINIZ, 2009, p. 7 e 8).

Com efeito, a responsabilidade civil respalda as relações humanas de cunho jurídico, trata-se do instituto que regulamenta a liberdade do agir individual e, por conseguinte, seus reflexos na sociedade. Embora consideravelmente recente, por sua dinamicidade, apresenta significavas modificações ao longo do tempo, expondo a sua flexibilidade de acordo com as necessidades relacionais dos indivíduos.

Breve retrospectiva histórica é útil para a compreensão do fundamento, evolução e estado atual do sistema da responsabilidade civil. Fundamento da responsabilidade civil é a razão por que alguém deve ser obrigado a reparar o dano causado a outrem. Na primeira fase do processo histórico foi a culpa e, posteriormente, o risco de um dano, como consequência de certas atividades produtivas desenvolvidas pelo agente causador do prejuízo (AMARAL, 2014, p. 603).

Em seu contexto histórico, a responsabilidade civil apresenta diversas conotações, as quais seguem tutelando o bem e o dever jurídico imposto por determinado ordenamento. A explanação feita sobre a origem do dano (código de Hamurabi) remete à essência da responsabilidade civil, traduzida em reparar o mal que se causou a outrem, com a diferença de que no início se tratava mais de uma vingança privada, do que uma reparação (DINIZ, 2007, p.11). 
Já a Lei das XII Tábuas reconheceu a composição obrigatória, exigindo da vítima a renúncia à pena privada e a aceitação da indenização designada pelo Estado (nessa fase não se diferenciava responsabilidade penal de civil) (AMARAL, 2014, p.604).

Na sequência, surge a referência da Lex Aquilia, a qual abalizava a distinção entre responsabilidade extracontratual e contratual, entretanto, mais do que isso, registrou a origem do elemento culpa como sustentáculo da reparação do dano (PEREIRA, 2002, p. 4).

Com a consagração do elemento culpa, caracterizada com a ocorrência do ato ilícito, independente de uma relação jurídica pré-estabelecida, a responsabilidade civil retrata o caráter subjetivo. Anderson Schreiber ao analisar as colocações de Jeans-Jacques Wunenburger pondera que a responsabilidade passa a ser puramente civil e alicerçava-se no uso culpável da liberdade, que moralmente demandava uma sanção (SCHREIBER, 2013, p. $12-13)$.

Em linhas gerais, a inserção deste elemento, atualmente previsto no artigo 186 do Código Civil brasileiro de 2002 (artigo 159 do Código Civil de 1916), acarreta a vítima o ônus de provar a culpa ${ }^{11}$ do agente que lhe causou dano (CARVALIERI FILHO, 2005, p. 39).

Ocorre que o contexto histórico por volta dos séculos XVIII e XIX remete à revolução industrial e tecnológica, com a propagação dos meios de transportes e o enredamento das relações sociais, apresentando novas situações e, com isso, o aumento dos acidentes, que não poderiam mais ser suportados pela culpa (AMARAL, 2014, p.604).

A necessidade da vítima demonstrar a culpa do agente não mais se enquadrava nas relações modernas, em que inúmeras vezes o dano era clarividente, mas a impossibilidade de provar a culpa afastava a vítima de uma reparação justa.

Isso acabou por ocasionar um repúdio da própria sociedade e do próprio órgão judiciário, que, por vezes, encontravam-se impedidos de agir. Era preciso apresentar uma solução, pois afastando o elemento moral, a finalidade a ser alcançada se traduzia de forma objetiva, de simples reparação e não interior e subjetiva, como na imposição da pena (LIMA, 1960, p.120).

Em resposta a isso, após uma intensa investigação de critérios a serem adotados para a composição da responsabilidade que não tivesse como elemento central a culpa, surge a

\footnotetext{
${ }^{11}$ Para Arnaldo Rizzardo, a culpa em sentido estrito pode ser considerada aquela que traça a conduta imprudente ou negligente. Já a culpa em sentido amplo consiste na prática consciente e deliberada de uma ação prejudicial e antissocial (2015, p. 03).
} 
responsabilidade civil pelo risco. No Brasil, ainda que sinalizada no Código Civil de 1916, a responsabilidade pelo risco se consolidou de maneira positivada por meio de diplomas especiais, como por exemplo, a Lei das Estradas de Ferro (Decreto n. 2.681-12) e o Código Brasileiro de Aeronáutica (Lei n. 7.565-86) (SCHREIBER, 2013, p. 20).

A chamada teoria do risco, oriunda das atividades que por sua própria execução desempenhavam risco eminente, concebia a ideia de que o dano deve ser indenizado independentemente de culpa. Na sequência, essa teoria serviu de substrato para fundamentar a responsabilidade objetiva que, conforme previsão legal, imputa ao agente causador do dano o dever de reparação independente de culpa, mesmo que não inserido em uma atividade de risco (CARVALIERI FILHO, 2005, p. 40).

Nessa conjuntura, é possível perceber que o instituto da responsabilidade civil voltase mais para a conduta do ofensor na busca do ressarcimento efetivo do dano. Ademais, conforme já explanado, a consagração do princípio da dignidade humana ocasionou uma sistemática extensão da tutela da pessoa da vítima, aumentando expressivamente as hipóteses de dano ressarcível (MORAES, 2007, p. 237).

O anseio de imputar ao causador do dano o dever de repará-lo traduz o mais elementar sentimento de justiça. Dessa forma, é possível concluir que o verdadeiro fundamento da responsabilidade civil é reestabelecer o equilíbrio relacional, o qual se realiza por meio do dever de reparar ou compensar o bem ou interesse juridicamente tutelado (CARVALIERI FILHO, 2005, p. 39).

Isso porque o indivíduo não mais se insere em abstrato e individualizado egoisticamente, mas como pessoa comprometida com o social (princípio da solidariedade). A responsabilidade civil se revela como dever ético-jurídico de cumprir uma prestação de ressarcimento (AMARAL, 2014, p. 602).

Entretanto, não há responsabilidade, em qualquer modalidade, sem violação do dever jurídico preexistente, uma vez que responsabilidade pressupõe o descumprimento da obrigação e para se identificar o responsável é necessário precisar o dever jurídico violado (CARVALIERI FILHO, 2005, p. 27).

Dessa forma, o instituto da responsabilidade civil resguarda em sua essência a função ressarcitória, a qual visa ao reequilíbrio relacional dos indivíduos inseridos em sociedade. É preciso, pois, saber a qual bem ou interesse juridicamente relevante a tutela recai, para que 
identificando o dever jurídico lesionado; logo, o dano a ser reparando ou compensado, a responsabilidade civil possa, então, cumprir de forma justa e efetiva a sua finalidade.

\section{CONSIDERAÇÕES FINAIS}

O desenvolvimento do presente estudo possibilitou a compreensão do dano extrapatrimonial como gênero, distinguindo-se de dano moral. Observa-se que o dano moral deve ser delimitado por meio dos valores éticos do individuo inserido em uma determinada sociedade e não por seus efeitos (dor e sofrimento). Já o dano extrapatrimonial, por abranger os danos de caráter existencial, conceitua-se de forma ampla e generalizada, como a ofensa aos bens e interesses jurídicos que não denotam de cunho econômico.

Além disso, considerando todo o contexto histórico decorrente das atrocidades do pós-guerra, bem como o desenvolvimento de novas tecnologias, evidencia-se a necessidade de estabelecer parâmetros de proteção ao sujeito enquanto pessoa concretamente considerada.

Em resposta a essa necessidade, despontou-se uma movimentação internacional, por meio de tratados e convenções, estabelecendo-se no Brasil como princípio jurídico previsto no texto constitucional, a dignidade da pessoa humana, a qual trouxe em sua essência que todo indivíduo carrega em si próprio a dignidade, devendo ser tratado com o mesmo respeito e consideração que o seu semelhante.

Com efeito, essa nova concepção não ficou à margem da previsão constitucional, ao contrário, ecoou por todo o ordenamento jurídico. O princípio da dignidade da pessoa humana, em razão de sua carga valorativa, estabeleceu-se como vetor supremo da análise de toda e qualquer questão jurídica.

Dessa forma, há uma ampliação dos direitos e interesses juridicamente relevantes a serem considerados sob o aspecto existencial do homem, como por exemplo, os direitos fundamentais, os direitos da personalidade, o próprio direito à liberdade vinculando-se a autonomia do indivíduo frente à evolução das civilizações complexas.

Em matéria de Direito Civil, observou-se uma extensão das relações jurídicas de cunho existencial, uma vez que, fundamentados na evolução histórica e atual, novos direitos despontaram, consequentemente, quando lesionados, novos danos. Não obstante, reflexos dessa nova conotação atingem o instituto da responsabilidade civil, o qual envolve as relações jurídicas, bem como os elementos de sua composição estrutural, em destaque, o dano. 
Na estrutura de uma relação jurídica o dano indica a ocorrência de uma lesão a algum bem ou interesse juridicamente relevante, fazendo nascer o dever de indenizar do agente. A vítima deve ser ressarcida para que então, se reestabeleça-se a harmonia relacional.

Nas relações jurídicas patrimoniais, conforme visto, a sistemática é bem lógica, pois o dever de indenizar se trata da diferença entre o que se tem e o que se teria, não fosse a lesão. Já nas relações existenciais, o dano decorre das ofensas a bens e valores que não expressam conteúdo econômico, por essa razão diversas doutrinas nomeiam essa lesão como dano moral.

Entretanto, a dicotomia estabelecida entre as relações jurídicas patrimoniais e não patrimoniais sintetizadas, consecutivamente, por danos aos bens materiais e danos morais, não mais se apresenta satisfatória. O conceito de dano moral apresentado pela doutrina clássica, em verdade, adequa-se melhor ao dano extrapatrimonial, sendo este gênero e não espécie.

Isso porque, o dano moral está coadunado à lesão a um direito ou interesse juridicamente relevante, que não necessariamente se traduza em ofensa aos direitos da personalidade, mas na lesão aos valores éticos do homem concretamente considerado.

Assim, constata-se que o dano extrapatrimonial, considerado como gênero, possibilita o ensejo a uma proteção jurídica com mais ênfase aos direitos e interesses, tais como, o moral, o existencial, personalíssimo, dentre outros que decorrem da proteção da pessoa em seus diversos fragmentos, possibilitando que o instituto da responsabilidade civil cumpra de maneira eficaz e justa a sua função ressarcitória.

\section{REFERÊNCIAS}

AMARAL, Francisco. Direito Civil: Introdução. Rio de Janeiro: Renovar, 2014.

AMARANTE, Aparecida I. Responsabilidade civil por dano à honra. $6^{\mathrm{a}} \mathrm{ed}$, revista atualizada e ampliada. Belo Horizonte: Del Rey, 2005.

BITTAR, Carlos Alberto. Responsabilidade civil por danos morais. São Paulo: Revista dos Tribunais, 1994.

BONAVIDES, Paulo. Teoria Constitucional da Democracia Participativa. São Paulo: Malheiros, 2001.

BRASIL. Constituição (1988). Constituição da República Federativa do Brasil: promulgada em 05 de outubro de 1988. In: Vade Mecum Saraiva/ obra coletiva de autoria da Editora Saraiva com a colaboração de Livia Céspedes e Fabiana Dias da Rocha. - 22. ed. atual. e ampl. - São Paulo: Saraiva, 2016. 
Código Civil. Lei n. 10.406 de 10 de janeiro de 2002. Vade Mecum Saraiva/ obra coletiva de autoria da Editora Saraiva com a colaboração de Livia Céspedes e Fabiana Dias da Rocha. - 22. ed. atual. e ampl. - São Paulo: Saraiva, 2016.

Código Civil dos Estados Unidos do Brasil. Lei n. 3.071 de $1^{\mathrm{o}}$ de janeiro de 1916. Disponível em: < http://www.planalto.gov.br/ccivil_03/leis/L3071.htm>. Acesso em: 18 de mai. 2017.

CAVALIERI FILHO, Sérgio. Programa de responsabilidade civil. São Paulo: Malheiros, 2005.

DIAS, José de Aguiar. Da responsabilidade civil. Rio de Janeiro: Forense, 1994.

DINIZ, Maria Helena. Curso de Direito Civil Brasileiro, $7^{\circ}$ volume: Responsabilidade Civil21.ed.rev. e Atal de acordo com o novo CPC, São Paulo: Saraiva, 2007.

Curso de Direito Civil Brasileiro. $5^{\circ}$ volume. São Paulo: Saraiva, 2009.

FACHIN, Luiz Edson; PIANOVSKI, C. E. A dignidade da pessoa humana no direito contemporâneo: uma contribuição à crítica da raiz dogmática do neopositivismo constitucionalista. Revista Trimestral de Direito Civil, v.35, jul./set. 2008.

FACCHINI NETO, Eugênio. Da responsabilidade civil no novo código. In: Revista do Tribunal Superior do Trabalho, Porto Alegre, RS, v. 76, n. 1, p. 17-63, jan./mar. 2010. Disponível em: <https://juslaboris.tst.jus.br/handle/1939/13478>. Acesso em: 18 de mai. de 2017.

FENSTERSEIFER, Nelson Dirceu. Dano extrapatrimonial e direitos fundamentais. Porto Alegre: Sergio Antonio Fabris Ed., 2008.

FREITAS, Claudia Regina Bento de. O Quantum Indenizatório em Dano Moral: Aspectos Relevantes para a sua Fixação e suas Repercussões no Mundo Jurídico. Rio de Janeiro. Escola de Magistratura do Estado do Rio Janeiro, 2009.

LIMA, Alvino. Culpa e risco. São Paulo: Revista dos Tribunais, 1960.

LOPES, Miguel Maria de Serpa. Curso de direito civil. Fontes acontratuais das obrigações Responsabilidade civil. $5^{\text {a }}$ ed. Rio de Janeiro: Freitas Bastos, 2000.

LOPEZ, Teresa Ancona. $O$ dano estético: responsabilidade civil. São Paulo: Revista dos Tribunais, 2004.

MIRANDA, Pontes de. Tratado de Direito Privado. Tomo XXVI. 1959.

MORAES, Maria Celina Bodin de. Danos à pessoa humana: uma leitura civil-constitucional dos danos morais. Rio de Janeiro: Renovar, 2003. 
A constitucionalização do Direito Civil e seus efeitos sobre a Responsabilidade Civil. In: SOUZA NETO, Cláudio Pereira de; SARMENTO, Daniel (orgs). A constitucionalização do direito. Fundamentos teóricos e aplicações específicas. Rio de Janeiro: Lumen Juris, 2007. Disponível em:

http://egov.ufsc.br/portal/sites/default/files/a_constitucionalizacao_do_direito_civil_e_seus.pd f. Acesso em: 06 de mai. 2017.

NEGREIROS, Teresa. Teoria do contrato: novos paradigmas. $2^{\mathrm{a}}$ ed. Rio de Janeiro: Renovar, 2006.

PEREIRA, Caio Mario, Responsabilidade Civil, Rio de Janeiro: Forense, 2002.

PERLINGIERI, Pietro. Perfis de Direito Civil/Pietro Perlingieri; tradução de: Maria Cristina de Cicco. $2^{a}$ ed. Rio de Janeiro: Renovar, 2002.

PIOVESAN, Flávia. Direitos humanos e o direito constitucional internacional. $4^{\mathrm{a}}$ ed. São Paulo: Max Limonad, 2000.

RIZZARDO, Arnaldo. 1942. Responsabilidade civil. 7. ed. rev. E atual. Rio de Janeiro: Forense, 2015.

SARLET, Ingo Wolfgang. Dignidade da pessoa humana e direitos fundamentais na Constituição Federal de 1988. Porto Alegre: Livraria do advogado, 2008.

SARMENTO, Daniel. Dignidade da pessoa humana: conteúdo, trajetórias e metodologia. $1^{\mathrm{a}}$ edição. Belo Horizonte: Fórum, 2016.

SCHREIBER, Anderson. Direitos da Personalidade. São Paulo: Atlas, 2013.

SEVERO, Sérgio. Os danos extrapatrimoniais. São Paulo: Saraiva, 1996.

SILVA, Almiro do Couto e. A responsabilidade extracontratual do Estado no Direito. In: Revista do Direito Administrativo. Rio Janeiro: Livraria e Editora Renovar Ltda, v.1. 1991.

TARTUCE, Flávio. Direito Civil, v. 2: direito das obrigações e responsabilidade civil. $11^{\text {a }}$ ed, atualizada e ampliada. Rio de Janeiro: Forense. São Paulo, Método, 2016.

TEPEDINO, Gustavo. Código Civil interpretado conforme a Constituição da República. Vol. 1. Rio de Janeiro: Renovar, 2004.

THEODORO Junior, Humberto. Dano Moral. $7^{\mathrm{a}}$ ed, atualizada e ampliada. Belo Horizonte: Editora Del Rey, 2010.

VÁZQUEZ. Adolfo Sánchez. Ética. 28. ed. Rio de Janeiro: Civilização Brasileira, 2006.

VIEIRA, Jair Lot. Código de Hamurabi - Lei das XII Tábuas, Código de Manu (Livros Oitavo e Nono). Editora Edipro, 2011. 
ZANETTI, Fátima. A problemática da fixação do valor da reparação por dano moral: um estudo sobre os requisitos adotados pela doutrina. São Paulo: LTr, 2009. 